\title{
The Study on the Construction of WeChat Public Platform Based on Basketball Teaching
}

\author{
$\mathrm{Li} \mathrm{Liu}^{1}$ \\ Tangshan industrial Vocational Technical College \\ Tangshan, China \\ E-mail: liliutougao@126.com \\ Kun $\mathrm{Sha}^{3}$ \\ Tangshan College University Sports Department \\ Tangshan, China \\ E-mail: 29463989@qq.com
}

\author{
Guoxi Yin ${ }^{2}$ \\ Tangshan Vocational \& Technical College \\ Tangshan, China \\ E-mail: 29463989@qq.com \\ Bin $\mathrm{Gao}^{4}$ \\ Hebei Institute of Physical Education \\ Shijiazhuang, China \\ E-mail: 29463989@qq.com
}

\begin{abstract}
Objective: Faced with the new media network environment, WeChat public platform as the carrier of modern information, will make WeChat dock with the campus information system of sports teaching, and make students query various kinds of campus sports information and teaching information by WeChat public platform. Methods: The Construction of WeChat public platform based on basketball teaching, can make the basketball teaching to keep pace with the times, fully response student cultivation mode, innovative teaching methods, expand teaching field, reform teaching mode, make network technology truly for the sports education service, can make full use of modern information technology, realize the teachers and students instant, convenient communication and interaction after class.Results: Based on this ,this paper studies the construction of WeChat public platform based on basketball teaching. First this paper introduces the basic function, characteristic and measure of merit of WeChat public platform. Then, this paper studies the construction of WeChat public platform based on basketball teaching.
\end{abstract}

Keywords-New Media; WeChat Public Platform; Basketball Teaching; Campus Information System; Construction

\section{INTRODUCTION}

Basketball [1] is one of the most favorite sport for contemporary college students, especially as NBA, CBA and CUBA and the college students' sports such as basketball super league basketball matches vigorous development, basketball is becoming a part of students' study and life. Basketball course in the university college courses is one of the most popular. With the development of the society, people's work, living conditions and modes have taken place great changes, which makes people's need for sports has been changed. Many traditional basketball teaching thoughts, goal, task, method, means, specific requirements, etc. have been difficult to meet the needs of students, nor is suitable for the requirements of the Times, so the basketball teaching in colleges and universities' change must be taken. WeChat public platform [2] as the carrier of modern information, will make WeChat dock with the campus information system of sports teaching, and make students query various kinds of campus sports information and teaching information by WeChat public platform. Based on this, this paper studies the construction of WeChat public platform based on basketball teaching.

\section{WECHAT PUBLIC PLATFORM RELATED OVERVIEW}

This chapter includes three parts, namely, basic functions, characteristics, and validity test vat.

\section{A. Basic Functions}

WeChat public platform's basic functions [3] include information management, user management, mass message, material management, settings, statistics and advanced functions, etc.

Message management[4] refers to that through realtime message interface can provide users with the 1 on 1 conversation solutions services, WeChat public platform can support login more than one at the same time, if you need to answer the user more, it can arrange customer service people to do human responses[5]. User management refers to that through that function, we are grouped according to the user's preferences, location, and the user's major. Mass messages can be edited voice, pictures, text, video and other media forms, after editing mass messages based on user groups for mass.

Material management refers to that through material management function, we can store for daily video, voice, images or other information, which is convenient to make the content of the reply in the future. Settings refers to through the account information we can set WeChat public account WeChat ID, image design, function of qr code, etc.

The statistical function [6] is composed of three parts: user analysis, graphic analysis and message analysis. The user analysis with corresponding graph and data table to display the user data, and in user attributes and view the user's gender, language, province distribution number and proportion of each; graphic analysis can see graphic message of each article how many users receive, reading quantity, the original pages read articles sharing forwarding number and number of times and times, etc. News analysis is to view the user to public account to send the message count.

Advanced features are composed of two modes of editing mode and development mode. The edit mode can realize the user subscription reply, any words and keywords reply, and use voice, text, images, video and 
other media forms to edit a reply message. After the development mode, can be used to the interface which is provided by the public platform.

\section{B. Characteristics}

WeChat as Internet new media form, has its distinctive traits.Basic understanding of the characteristics of WeChat [7]: WeChat were stratified media ecology. Media Ecology layered WeChat public platform as shown as Figure.1 [8].

From Figure.1 we can know that Micro-channel has the following characteristics. WeChat such media have concerns, real-time communication, sharing and other basic functions. WeChat can use voice, image, text, video and other forms of media to edit the information content of micro-channel. WeChat public account is updated by the computer and the public phone assistant number and send a message, the user receives via smart phones, tablet computers and other portable devices; WeChat public platform on the basis of the new function module of Tencent micro letter, which is an important part of the micro-channel system.

Through the above analysis, micro-channel public platform has the following characteristics:

Miniature sex. There is a miniature of information from a number of small forces spread. You can say that the formation of a micro-channel micro-propagation.

Own media properties. The general public and organizations can access anytime, anywhere, and connected to the global knowledge system is a real-time sharing their own facts and news channels.

Service and Reach. Micro letter is based on personal relationships, the availability of e-mail alerts, voice contact and other service functions also have privacy protection features, enabling users to avoid being harassed useless information.

\section{Validity Test Vat}

Studies have shown that learning effectiveness tests and the results were learning test found no significant difference in a laboratory environment under real environment, under limited conditions, in the laboratory environment to analyze the learning test learning resources and learning miniature effect is entirely feasible. In a lab environment to test learning. Test environment are as follows: smart phones, users, micro-channel, and micromobile learning resources as well as researchers, which is shown as Figure.2.

\section{THE CONSTRUCtion OF WeChat Public PLATFORM BASED ON BASKETB ALL TEACHING}

\section{A. The Construction of Basketball Teaching based on We Chat Public Platform}

Build a micro-channel public platform generally includes registration, activation, auditing, marketing four processes. Use the browser to open micro-channel public platform website, click on the "Register Now" and follow the instructions and complete the registration of basic information; after basic information is complete, the link address mail to activate send, then log in micro-channel platform to fill other information; information after registration filled, generally require seven days waiting for review, prior to approval, the public account can only achieve the basic operation. Physical Education Teaching micro-channel structures of the same public platform through the above process, and then into the vast wealth of sports education information, the students get to meet the demands of sports knowledge.

\section{B. Design of Basketball Teaching Micro-Channel Public Platform Function Module}

This chapter functional module design [9] PE Basketball Teaching micro-channel public platform as an example. PE Teaching micro-channel public platform function module design is based on the PE Teaching Network Platform Colleges convergence and vocational college students living habits, personality characteristics.

Vocational college students [10] are now 90 young generation, they are the first to enjoy and promoter of all the new technology, which is the main force of social groups and the leading edge of new technology or new ideas. Universities educators as new media age, it must adapt to changes in college students' learning habits and communication mode 90, guided and communication channels through college students like to receive the majority of 90 students welcome. Based on this, in November 2013 on a micro-channel public platform for the "Yu Ying of Physical Education (yytyjx)" public numbers every day to focus on the platform of teachers and provide physical education, sports injuries, information security category, but also immediate reply student counseling related to physical health testing.

Given the set of Physical Education network platform, features a modular architecture handheld learning platform revolves around the status quo of Physical Education school itself, curriculum, physical health test, sports injuries and other emergency treatment to build. Features and advantages of micro-channel public platform are: high aging interpersonal, convenient operation, rich content and precise promotion push message, a very easy interaction between teacher and student. Teachers in the process of micro-channel platform can guide students to learn in micro letter platforms, it can also guide students to build a collaborative learning platform between students in the micro letter, practical ability and collaboration capabilities of students in this process. Based on this, the author architecture of PE teaching basketball micro-channel public platform function module [11], shown as Figure 3.

\section{Positive Effects}

As the network technology and the rapid development of information technology, 90 students were trained to nurture networks of knowledge, vast amounts of network information to enable them knowledge but broad diversification, micro-channel, microblogging, QQ and other new media appears, change the Students access to information and communication ways. Students can occur at any time through the university campus in many public platform for the exchange of learning, we want to learn new knowledge, new technology. Is a network platform to attract and nurture the same time, they pay attention to the physical health but particularly inadequate, particularly the function and role of sports-related knowledge and understanding of physical education is very weak.

The emergence of sports teaching micro-channel public platform that allows students to learn to set the course of 
the school year in sports platform to learn a variety of sports options for courses, so that students understand the relevant circumstances as soon as possible; understanding of the relevant PE teachers basic personal information and Specific requirements to participate in extracurricular sports clubs, especially for freshmen particularly needs; in sports encyclopedia, fitness and recreation function module, allows students to learn anytime, anywhere to understand the movement of the referee knowledge, motor skills and learning methods encounter during exercise Damage to aid knowledge; Also, you can grasp the physical evaluation criteria currently being implemented by the National Students Physical Health in order better to keep fit. Micro-channel platform of vivid, interactive for students to create a lively, easy to divergent thinking exploratory learning atmosphere, students will some sports knowledge, physical training methods to transform the platform into a method of their own design after will produce a sense of eager, to achieve better results when tasted the joy of success after they produced a sense of accomplishment, while promoting its own will be more positive, proactive thinking, create some better exercise prescriptions and programs, which will help improve students' ability to self-inquiry learning the sport.

Figures and Tables

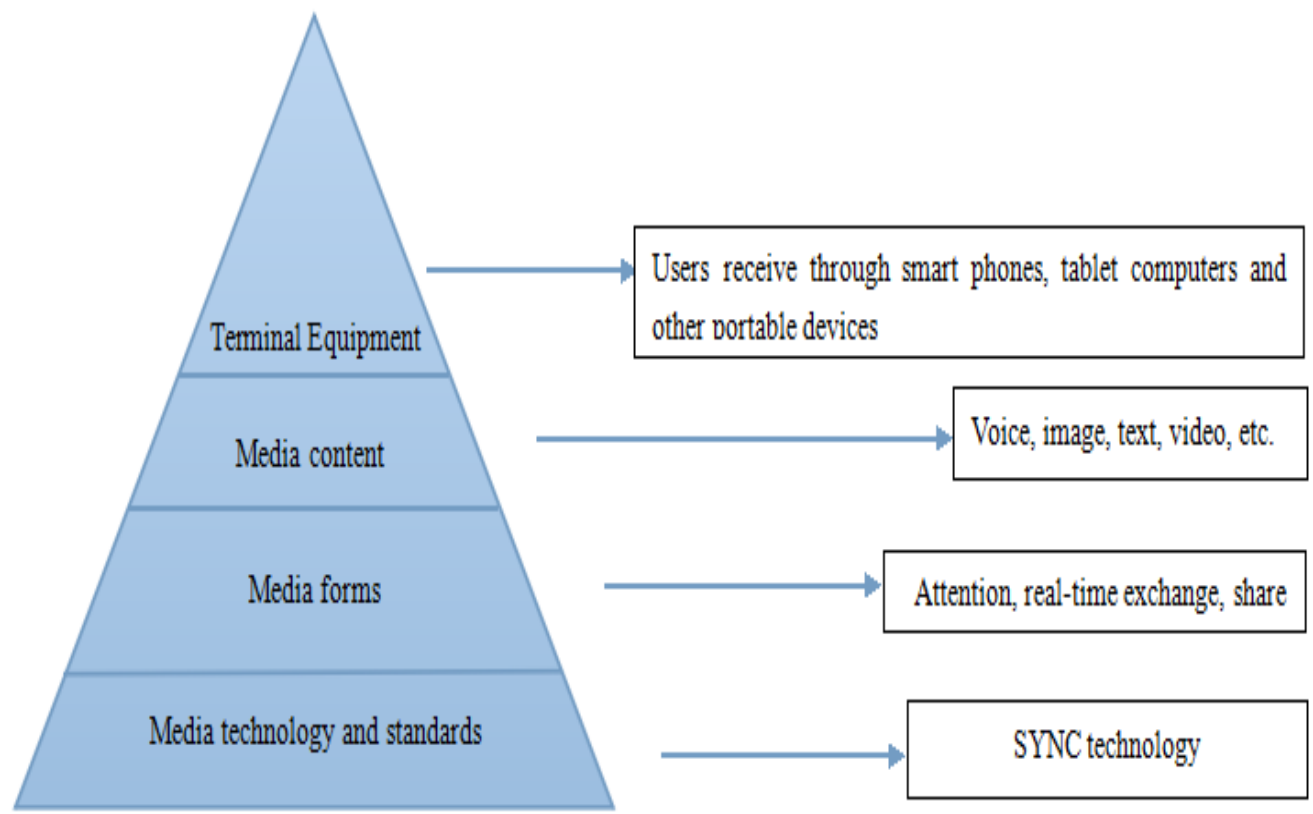

Figure 1. Media Ecology Layered Analysis based on WeChat Public Platform

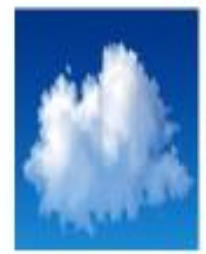

Miniature Leaming Resources

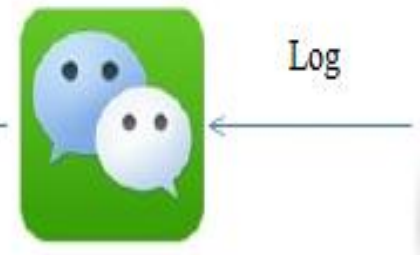

Webchat

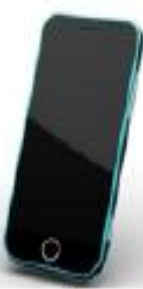

via
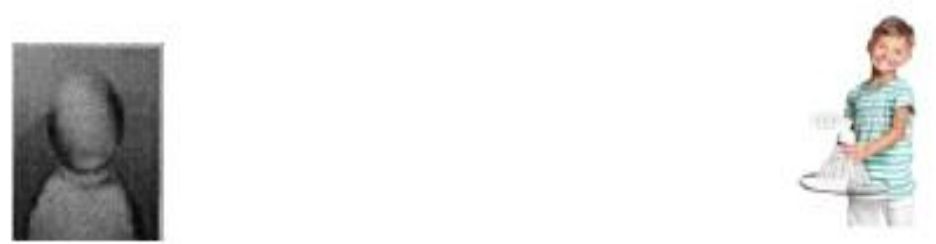

Researcher

User

Figure 2. Miniature Learning Resources Learning Test Chart 


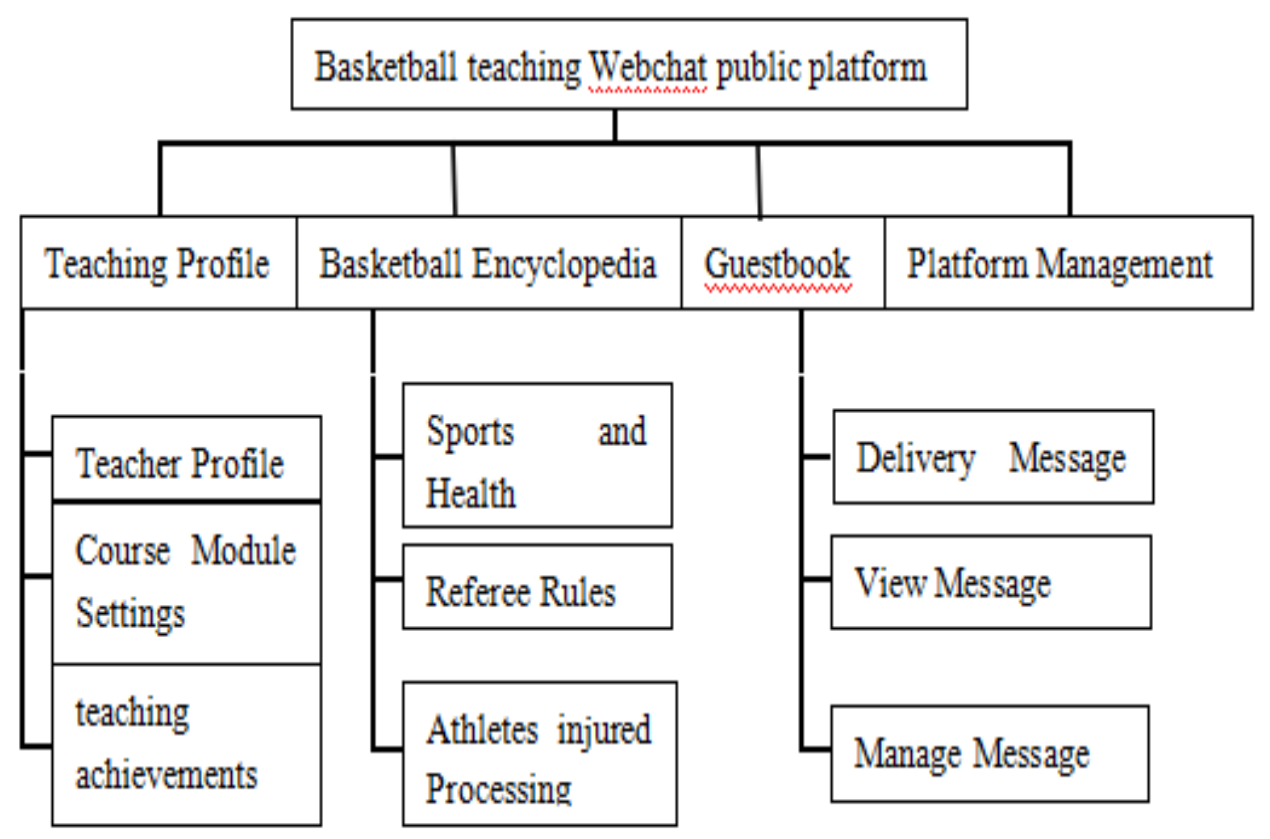

Figure 3. Basketball Teaching's Construction based on WeChat Public Platform

\section{CONCLUSIONS}

Basketball is one of the most favorite sport for contemporary college students. With the development of the society, people's work, living conditions and modes have taken place great changes, which makes people's need for sports has been changed. Many traditional basketball teaching thoughts, goal, task, method, means, specific requirements, etc. have been difficult to meet the needs of students, nor is suitable for the requirements of the Times, so the basketball teaching in colleges and universities' change must be taken. WeChat public platform as the carrier of modern information, will make WeChat dock with the campus information system of sports teaching, and make students query various kinds of campus sports information and teaching information by WeChat public platform.

So, this paper studies the construction of WeChat public platform based on basketball teaching. First this paper introduces the basic function, characteristic and measure of merit of WeChat public platform. Then, this paper studies the construction of WeChat public platform based on basketball teaching.

About the basic function, we discussed the WeChat public platform's information management, user management, mass message, material management, settings, statistics and advanced functions. About the characteristic, we discussed miniature sex, own media properties and service and reach.

About the construction of WeChat public platform based on basketball teaching, we discussed from the construction of Basketball teaching based on Webchat public platform, design of Basketball teaching microchannel public platform function module.

\section{REFERENCES}

[1] F. L. Yi. "90 Characteristics of College Students in Physical Education and innovative teaching mode" J. School of Physical Education, 2012.

[2] Y. Z. Cai. "Development and Research Engineering Network Platform Combination of Physical Education in Higher Colleges "J. Sports, 2012.

[3] L. L. Zhang. "The use of micro-channel public platform for college students to work in safety education "J. New West, 2013.

[4] X. X. Deng. "Empirical Study micro-channel public platform assisted classroom teaching" J. Modern computers, 2014.

[5] R. Hu. "Beijing Youth College Students micro-channel use in teaching the application prospect analysis "J, 2014.

[6] Y. T. Liu. "Research on micro-channel public platform in mobile learning application" J. software GUIDE (educational technology), 2013.

[7] T. Yao. "Micro-based learning design and development of mobile phone games" D. Zhejiang Normal University, 2012.

[8] W. F. Sheng. "Micro-channel platform operators campus public policy research "J. Jiannan literature (classic teaching Court), 2013. Pp: 318-319.

[9] Kaikkonen.A, Kelcalainen.A, Cankar.M, Ka11io.T, Kankainen.A. (2005).Usability Testing of Mobile Applieations: A Comparison between Laboratory and FieldTesting. UPA 'S Journal of Usability Studies: 4-16.

[10] C. L. Zhang. "Construction of community-based micro-channel network of interpersonal communication" D. Anhui University, 2013.

[11] Martin Lindner, Peter A. Bruce Micromedia and Corporate Learning: Proceedings of the $3^{\text {rd }}$ International Microlearning2007 Conference M. Innsbruck: Innsbruck University Press, 2007.8. 